\title{
"El siervo fiel no esconde el tesoro". Propuestas para enseñar y trabajar en Historia. Hechos abiertos al mundo que les rodea
}

\author{
Francisco Javier MARÍN \\ Universidad de Murcia \\ orfeo.pan@gmail.com
}

\begin{abstract}
Resumen:
La lectura de numerosos trabajos de investigación en Historia nos permite "almacenar" resultados compartimentados. Considerando tales resultados como positivos desde el punto de vista del desarrollo de la ciencia histórica, presentamos aquí otra opción. Nuestro interés se centra en conseguir que la investigación en Historia: "no sólo abarque la Historia" en las prácticas docentes; obtenga resultados eficientes en la forma de pensar de quienes la estudian; no se sienta satisfecha con la acumulación de proyectos cerrados. Vincularemos los casos metodológicos a ejemplos temáticos de Edad Moderna.
\end{abstract}

Palabras clave: Contexto histórico; cultura; metadatos; visión interdisciplinar; estudio; desarrollo

\section{“The faithful servant does not hide his treasure' Proposals for teaching and studying History. Facts opened up to the world around them}

\begin{abstract}
:
Reading several research papers in History allows us 'to store' fragmented results. Taking into account these results as positive, from the point of view of the historical science development, a new option for doing so is presented below. Our interest is focused on History research to reach three objectives: to embrace 'History' when teaching, to obtaining efficient and useful results for those who study it, and to develop methodological studies opened to future researches. Methodological cases will be related to thematic examples from the Modern Age.
\end{abstract}

Key Words: Historical context; culture; metadata; interdisciplinary vision; study; development

\section{Referencia normalizada:}

Marín, F. J. (2014): "El siervo fiel no esconde el tesoro". Propuestas para enseñar y trabajar en historia. Hechos abiertos al mundo que les rodea. Historia y Comunicación Social. Vol. 19. Núm. Especial Marzo. Págs. 375-385.

Sumario: 1. Introducción: descomponer el título, recomponer nuestra visión. 2. Metodología: marco y agente. 3. Ser o no ser "humanista": he ahí el verdadero estado de la cuestión. 4. Ser de nuestro tiempo: estudios y datos que trascienden. 5. Conclusión: ser que piensa y enseña activamente. 6. Bibliografía. 


\section{Introducción: descomponer el título, recomponer nuestra visión}

[...] cosecho donde no sembré y recojo donde no esparcí.

Si por algo pretende caracterizarse el presente estudio es por otorgar importancia a cada unidad temática del discurso, con una dialéctica interna que llega a confrontar elementos de un mismo epígrafe para mostrar hasta qué punto el lenguaje, las herramientas de análisis y los procesos de estudio pueden ofrecer múltiples descripciones de una misma problemática. Pese a que el lector no encontrará nada que se le parezca a las altas pugnas de los clásicos Popper y Piaget sobre Epistemología, ciertamente hablaremos de conocimiento, de lógica, de enunciados... y de ciencia; porque la Historia es ciencia, y se comportará como tal en su más amplio sentido si con ella se trabaja, se aprende y se enseña con la sensibilidad y la curiosidad del que espera "recoger hasta donde no esparció".

Con el texto evangélico de Mateo 25 se abre el telón de nuestro trabajo. Ni la cita es baladí ni su colocación caprichosa. Para un guión resumido en pocas páginas, hasta el primer compás del preludio tiene que anticipar parte de la esencia de toda la obra. En este sentido, vamos a realizar propuestas de tipo metodológico utilizando como hilo conductor el contexto político-religioso y el panorama social y familiar de la Monarquía hispánica durante los siglos XVI y XVII, considerando el Concilio de Trento como el punto de gravedad del ejemplo histórico que intentamos exponer; así pues, si el enfoque religioso está presente en la composición de aquellos esquemas culturales sobre los que transcurre el Siglo de Oro castellano, habíamos de aludirlo cuanto antes. Por otra parte, entendemos que el talento de quien se acerca a la disciplina histórica radica en entender que hay precisamente más que ese "talento" recibido (por eso hablamos de "tesoro"), y que no hay resultados más pobres que aquellos que quedan escondidos y relegados a la categoría de "satisfacción investigadora personal", sin capacidad para expresar una forma de trabajar, sin potencial para convertirse en una propuesta abierta a futuras revisiones, sin posibilidad de sobrevivir al investigador.

Surgidos al amparo del grupo de investigación "Familia y Elite de Poder" de la Universidad de Murcia, dos proyectos de investigación ${ }^{1}$ nos pueden servir como ejemplos para argumentar muy brevemente el estado de la cuestión. De una parte, la fase de análisis comparativos en la que se encuentra "Nobilitas. Estudios y base documental de la nobleza del Reino de Murcia, siglos XV-XIX” pone de manifiesto la naturaleza de las que fueron sus primeras fuentes de estudio: rigurosos trabajos genealógicos de tipo monográfico que, sin embargo, carecían de dinamismo por no presentar una herramienta de análisis y de plasmación de datos abierta a nuevas investigaciones, adaptable a diferentes formatos de archivos, y "gráficamente viva", cuestión que "Nobilitas" intentan subsanar con sus propuestas. De otro lado, las sucesivas reuniones científicas centradas en el estudio de las familias como motor del conocimiento de la sociedad y sus cambios hasta la etapa contemporánea dan un paso más con "Realidades familiares en conflicto [...]", último de los episodios (hasta la fecha) de un variado grupo de investigadores, que en este momento amplían sus 
fondos documentales de análisis para alojar también tratadística y literatura en sus estantes, elementos que enriquezcan la visión del tejido social con los ingredientes teóricos de ese "imaginario" que envuelve a las gentes de los siglos XVII al XIX.

Por tanto, dos líneas de investigación vigentes plantean algunas de nuestras cuestiones de partida: la incapacidad de muchos trabajos historiográficos para presentar un formato abierto e integrador; y la necesidad de evolucionar en la valoración de determinadas fuentes como objetos de estudio histórico con suficiente entidad.

\section{Metodología: marco y agente}

La clave de este punto en nuestro trabajo radica en la última de las afirmaciones del título inicial:

[...] abiertos al mundo que les rodea". Pero, ¿Qué o quiénes han de estar abiertos a ese "mundo? ¿A qué mundo queremos aludir?

Responderemos antes a la segunda cuestión. La metodología no se define aquí como un conjunto de pautas o recursos que nos lleven a exponer un tema diferente, sino como el objeto mismo de estudio, elemento activo (más activo que nunca) que transita como constante entre todas las disciplinas que en algún momento pudieran tomarse como ciencias auxiliares de la Historia, así como modelo aplicado en otras ramas radicalmente diferentes pero que en la actualidad conviven con las técnicas de análisis histórico o con los medios de difusión del conocimiento. La metodología, por tanto, conforma un "propio mundo", un foco específico de atención.

Por ello, todos los agentes han de entender esta predisposición al estudio de la metodología. Esto es: a) métodos de investigación histórica que den cabida en sus discursos a un análisis con mayor variedad de fuentes, definiéndose los acontecimientos o problemáticas históricas descritas por un conjunto más rico de elementos que abran su perspectiva hasta ser capaces de reconstruir categorías tan complejas como "cultura"; b) principios normativos sobre los que se desarrollan otras disciplinas, y que establecen definiciones ajustadas de cuáles han de ser los pasos a dar por todas las líneas historiográficas; c) objetos de estudio más propios de otras ciencias hacia los que el historiador ha de ser sensible, otorgándoles una entidad y un espacio específicos y adecuados para enriquecer el contexto; d) técnicas de categorización y sistemas de difusión de los que los investigadores actuales han de ser conocedores (con todo lo que implica "conocer", y no "dominar", como veremos más adelante), con el objetivo de desarrollar lo que podríamos denominar "estudios metodológicamente abiertos"; y e) métodos de aprendizaje y análisis provenientes de otras disciplinas, perfectamente compatibles con la actividad docente del historiador, y más aún, recomendables como sistema de adecuación mental por parte del alumno para percibir cuestiones complejas y ordenar ideas hasta ser capaz de extraer constantes y, desde ahí, categorías. 
Y, ahora sí, retornando a la visión habitual de metodología como "marco" del trabajo que estamos llevando a cabo, describimos una forma de exponer nuestros principios desde un tema histórico como el estudio de la moral y la religiosidad en el primer período de la Edad Moderna para la Monarquía hispánica en relación con las funciones, roles y usos familiares, aludiendo a él cada vez que las propuestas deban concretizarse en casos particulares.

No es de extrañar, por tanto, que las referencias bibliográficas a las que podemos aludir abarquen tanto ámbitos como la iconografía o la espiritualidad en el Siglo de Oro hispánico, como debates filosóficos, matemáticos o metodológicos que entrañan múltiples problemas particulares, pero de los cuales emergen sugerentes principios para la profundización en temas puramente históricos o historiográficos.

\section{Ser o no ser "humanista": he ahí el verdadero estado de la cuestión}

"Nuestro investigador" no sabe de todo; pero sabe de las mil cosas "que en el mundo han sido"; es más, sabe que el mundo que fue ha sido (como poco) tantas cosas como lo es nuestro tiempo. Por ello, se prepara para "no saber de todo pero ser sensible a todo" y hacer despertar su curiosidad cuando una nueva fuente de estudio se cruza en su camino. Veamos tres casos prácticos vinculados a una misma temática de fondo.

Estudiando la tratadística moral y espiritual que florece al calor de las actas conciliares tridentinas, llega a nuestras manos un curioso libro editado por Carlos Sanz en 1962, titulado Estampas de la Vida de la Santa Madre Teresa de Jesús, y que contiene grabados de Galle y Collaert acerca de la vida de "la Santa Madre" (como es conocida en el Carmelo descalzo), recorriendo las sendas de la espiritualidad de la época y satisfaciendo ambos autores con cada una de sus ilustraciones la demanda de visiones y experiencias místicas que identificaban la biografía de tan insigne abulense (a pesar de no ser lo sobrenatural o lo morboso lo que más hallamos en sus escritos; pero por encima del legado de una prosa que pretende llegar al fondo del alma para empezar a conocerse y desprenderse de cuanto la ata -que en definitiva es todo aquello que pone barreras a la comprensión de la humanidad de Cristo y de acercamiento al ser humano-, su ambiente es el que es, y las generaciones que le suceden ven en los hechos corporales los signos más ilustrativos de santidad). Por tanto, estamos ante una obra "parca en palabras", y sin embargo, cada palabra dice mucho. Y entre ese escueto ramillete de explicaciones, nuestros ojos contemplan el brillo de su portada, que indica que estamos ante una obra ya impresa en Amberes hacia el año 1613. A partir de aquí, el libro ha sido incorporado al elenco de obras a estudiar a fondo; ha dejado de ser "referencia" para convertirse en "fuente". Y el motivo se encuentra en todo lo que nos "recuerda" esa cita: la ciudad de Amberes es el gran enclave comercial del norte de Europa durante todo el siglo XVI (hasta que despierte por completo Amsterdam), y a su vez es el hogar de algunas de las más importantes familias de 
impresores de toda la Edad Moderna. El desarrollo de la imprenta y las relaciones comerciales confieren a la ciudad tanta identidad como las propias actuaciones políticas y religiosas a las que se ven sometidos todos los territorios cercanos a partir de la reforma luterana y las tensiones que se agravan con el movimiento contrarreformista. Estudiar la religiosidad popular y el ambiente familiar hispánico desde la definición de sus tratados ha de conjugarse con un conocimiento básico de las relaciones comerciales que traen a las dos Castillas infinidad de obras impresas en otros puntos de Europa, obras editadas en castellano porque su destino se encuentra a muchos kilómetros de donde son estampadas aunque a la postre ambas "casas" (la del impresor y la del lector") están bebiendo de unos principios morales que se extienden por todo el mundo católico. Nuestro estudio puede seguir estando "localizado" (que no siendo localista), pero será a la vez vinculante (global y particular en una).

El segundo ejemplo también fue "causa de nuestra alegría" el día que lo encontramos. Se trata de una publicación que lleva por nombre Grabados Andaluces de San Juan de la Cruz (Bibliografia sanjuanista de los siglos XVII-XVIII), uno de tantos formatos de exposición que se suelen llevar a cabo cuando se pretende conmemorar un acontecimiento importante, y aquello que se celebra en 1991 (año de su edición) no es otra cosa que los cuatrocientos años de la muerte del santo. El libro confronta en muchas de sus ilustraciones grabados atribuidos a Arteaga y Zucchi, y en todas ellas láminas de autoría hispánica e italiana respectivamente. A partir de aquí, poco queda por argumentar: estamos ante una recopilación de grabados que ilustran las escenas más representativas del autor del "Cántico Espiritual" partiendo siempre de dos versiones prácticamente idénticas, originadas en Italia y en España, pesos pesados de la reforma católica del momento. Evidentemente, nuestro estudio no puede carecer de un encuadre geográfico que incite a observar la vinculación e interdependencia que promueven bulas, visitas ad limina, decretos, y también imágenes por lo que acabamos de observar ${ }^{2}$.

El tercer ejemplo termina de engalanar la exaltación de repertorios iconográficos en época postridentina. Se trata de la edición publicada en el año 2008 por la Universidad de Deusto de un clásico entre los potentes autores de la Compañía de Jesús, el Padre Jerónimo Nadal (SJ) y su obra Biblia Natalis, conjunto valiosísimo de ilustraciones que narran con detalle los diferentes pasajes que componen la vida de Cristo, con el lujo de encontrar a los pies de cada escena la leyenda que da nombre a cada personaje, conjugándose así nombre, acción y sentido religioso en grabados de gran calidad de los cuales se demandaron diferentes impresiones en las mismas postrimerías del siglo XVI, poco después de que la composición viera la luz. Y si los ejemplos anteriores nos llevaban a "otras historias", como la de la ciudad de Amberes o la de las relaciones de la Monarquía hispánica con Roma, este perfecto complemento que adecúa la Sagrada Escritura al sentido didáctico y al significado profundo que persiguen los ejercicios de Ignacio de Loyola pone sobre la mesa una línea más del tiempo, una nueva historia por contemplar paralela a las anteriores, la del nacimiento y desarrollo en sus primeras décadas de la Compañía de Jesús, en lo referente a la 
formación de sus protagonistas y la ingente producción literaria que llevan a cabo en favor del fortalecimiento de las prerrogativas tridentinas.

Tres nuevas fuentes, tres temas a los que se alude, y tres cronologías que hay que combinar con las dos que eran en el origen de nuestro estudio, la "básica historia política" capacitada para abrir y cerrar ciclos, y la pequeña cronología literaria que avanza de edición en edición de las obras morales estudiadas. Sin embargo, falto de sentido común está nuestro investigador si en la senda de su trabajo se va enamorando de cada nueva aparición, escogiéndolas a todas indiscriminadamente, haciendo de cada ellas un mundo... Pero he aquí que la elección de estas tres obras vino en su origen por una característica presente en las tres: sin reparar ahora en su localización precisa, todas ellas presentan al menos un grabado en el que se exalta la Eucaristía como Sacramento instituido por Cristo, misterio y núcleo de la fe; y esto no sólo estaba presente en las tres, sino en la mayor parte de los tratados morales y espirituales estudiados hasta ese momento. Por ello, lo que estas fuentes aportaban en un principio al hilo temático inicial eran nuevas acepciones para un mismo asunto capital del Concilio, como "Institución del Santísimo Sacramento y Sacrificio" (la obra del P. Nadal), "Eucharistiae Sacramentum [...]" (el grabado teresiano), y el comentario a los cobres sanjuanistas, más dados a explicitar aquello que buscábamos:

[...] y dijo su primera misa en el Convento de Santa Ana de Medina del Campo, momento que recoge el grabado, donde es confirmado en gracia, pues él pedía constantemente a Dios no caer en pecado, y así cuando consagró, se le apareció la Virgen para darle un lirio, símbolo tradicional de pureza, y un ángel le ciñó un cíngulo. ${ }^{3}$

La iconografía, el estudio de la imprenta, la literatura y la historia de las órdenes religiosas se han vestido de gala para ofrecer algunos de sus mejores frutos en pos de la comprensión de una sociedad "sólida y solidificada", "movida y móvil", bajo hechos que compusieron su devenir más cotidiano, y que por tanto intervinieron en la construcción de su cultura. Es esto parte de lo que nuestro investigador busca: ampliar fuentes de estudio situándolas en su debido lugar y ejerciendo sobre ellas un análisis adecuado de cara tanto a la idea original como a los nuevos componentes que integran una visión cada vez más completa (y sí, compleja...).

\section{Ser de nuestro tiempo: estudios y datos que trascienden}

Si hemos sido capaces de establecer las conexiones temáticas anteriores, se debe al conjunto de categorías previas sobre las que habíamos asentado nuestra concepción histórica de los cambios sociales. Tales categorías residen en un mundo de discursos que, o bien son expuestos por las fuentes documentales a las que nos acercamos, o en cierta medida proceden de las consideraciones previas con las que el historiador inicia un nuevo proyecto. De cualquier forma, nos estaremos refiriendo a construcciones o esquemas mentales que adecúan toda la información posterior a una orientación precisa (y en muchos casos necesaria). 
Cuando profundizamos en el campo de las tendencias historiográficas, descubrimos un vasto conjunto de factores ambientales, antropológicos, filosóficos, religiosos, políticos, que provocan una determinada dialéctica entre un resultado final y otro, ofreciendo dinamismo a los trabajos compuestos y permitiendo que ciertos debates se reabran casi de manera cíclica. Pero, más allá de eso, entendemos que la riqueza que esta circunstancia propicia es precisamente la capacidad para captar datos "periféricos" (que envuelven una acción, sin ser la propia acción) y transformarlos en categorías de análisis, conceptos definitorios que pueden abrir o cerrar las posibilidades de interpretación, pero que, al fin y al cabo, proyectan un uso más sistemático y depurativo.

Como el lector puede observar, estamos atendiendo a la parte del epígrafe en que hablamos de "datos [...] que trascienden". Vamos a presentar todas las posibilidades de "trascender" que presentan estos datos:

Determinados conceptos emergen rápidamente de una fuente documental a través de la aplicación de técnicas de análisis cuantitativo. Se aplican procesos mecánicos de mayor o menor complejidad hasta conocer, no sólo los términos más empleados, sino sus relaciones con otros tantos que componen desde su campo semántico hasta su contexto gramatical (sin hablar de su contenido histórico, pues eso lo dejaríamos para un siguiente paso). Llevado esto a cabo, analizamos cada concepto y marcamos una jerarquía entre ellos, ampliando o constriñendo la definición individual de cada uno según el valor particular del elemento y lo que supone para el conjunto de la fuente literaria, dando lugar a categorías de análisis más o menos estructuradas. Desde este estadio interviene el análisis cualitativo.

Otro proceso muy diferente, y que pudiera parecer que juega a la inversa, sería el de aplicar ese conjunto de categorías a conceptos posteriores, asimilando en la percepción de nuevas palabras enunciados que las aglutinan en diferentes principios teóricos o temáticos, conformando así los inicios de un método de trabajo.

No obstante, deberíamos conocer los objetivos de nuestro investigador. Si en su proyección de la cuestión abordada sólo observa un trabajo próximo a finalizar, entonces la primera opción es suficiente. Si, por el contrario, se resiste a pensar que "finalizar" vaya acompañado de "olvidar", entonces se preocupará de poner en marcha todo un conjunto de herramientas de análisis que trasciendan al propio estudio, convirtiéndolo en abierto en tanto que integrador, con la capacidad de ser finalizado por un investigador, pero con idéntico potencial para retomarse, desarrollarse y difundirse (en tanto "compartirse").

A partir de aquí, nuestro estudioso de la historia de la familia y los tratados morales del Siglo de Oro hispánico tiene la oportunidad de convertirse en un "ser de nuestro tiempo", observando las técnicas más básicas que se emplean en ciencias como la Informática cuando ésta se aplica a otras disciplinas ${ }^{4}$, y dejando que sus especialistas "metan sus narices" "donde se les ha de llamar con más frecuencia". En este intrincado debate (que no es nada nuevo), la salida está en un concepto básico: "metadatos". Cuando el dato trasciende y se convierte en categoría de análisis, aún 
le queda un camino por recorrer, y es lograr que, como flamante categoría que es, se convierta en principio de estructuración y catalogación de ideas para optimizar el trabajo de comprensión de fuentes. Los archivos de audio se componen de un pequeño escuadrón de metadatos que nos hablan de autores (personas), producción discográfica (hechos), año (cronología), y hasta estilo (naturaleza y temática). Los ficheros adaptados a estudios genealógicos albergan en su diseño un número amplio de atributos que dan vida a individuos (personas), hitos en su ciclo vital (acciones), año (cronología), espacios políticos o socioeconómicos (naturaleza y temática), y hasta relaciones.

En este sentido, la aplicación de metadatos confiere a categorías para el análisis histórico un atributo singular, transformándolas en vehículos de rápida estructuración de ideas y comprensión de un contexto en el que todas sus manifestaciones se van acoplando a los principios ya establecidos o inaugurando nuevas casuísticas, que al haber sido trabajadas desde un lenguaje informático, su representación puede estar al alcance de toda la comunidad científica. Desde esta postura, defendemos una expansión de los sistemas de asimilación conceptual para aplicar metadatos a elementos como los que arriba reproducíamos (iconografía, literatura, etc.).

Como última premisa de este apartado, la trascendencia de un estudio está marcada también por las características de quienes llevan a cabo la investigación. Y en ello, nuestra concepción está en armonía con los esfuerzos de transformación protagonizados por otras disciplinas. Desde materias que afectan a bibliotecarios y documentalistas, su objetivo por alcanzar una optimización del manejo de recursos y evolucionar en las facilidades de acceso queda reflejado en los Planes Estratégicos Rebium, dentro de los cuales, en un análisis superficial de los informes para 2003, 2007 y 2020, la evolución de sus contenidos parecen aportar una buena alternativa en el último de sus documentos:

Liderar, coordinar y dar directrices a las bibliotecas universitarias y científicas potenciando la cooperación y la realización de proyectos conjuntos para dar respuesta a los nuevos retos que las universidades tienen planteados en los ámbitos del aprendizaje, la docencia, la investigación y formación a lo largo de la vida.

\section{Conclusión: ser que piensa y enseña activamente}

El sentido fundamental, y por tanto, la reflexión conclusiva de todos los argumentos anteriores consiste en fomentar hábitos tanto de aprendizaje como de investigación que apuesten por introducir nuevas fuentes y disciplinas en el trabajo y en la difusión de resultados. De esta forma, entendemos que es desde la experiencia docente como se pueden poner a prueba estos procesos.

Son muchas y muy variadas las técnicas que pueden aplicarse en el aula universitaria para estimular algo mucho más básico y duradero que la información compilada, como es el "cómo" entender, juzgar y transmitir esa información. Desde las 
ciencias en las que se desarrollan trabajos documentales, nuestra "materia prima" (la fuente documental) permite ser trabajada mediante sucesivos puntos de vista para una mejor resolución de conflictos. Nos referimos a hábitos del proceso de conocimiento que trascienden la actividad docente y repercuten positivamente en la adquisición de métodos y esquemas de trabajo aptos para aplicarlos en cualquier área, como los "programas heurísticos" traídos del mundo de las Matemáticas con la visión de Poyla sobre el trabajo de enunciados, la fragmentación en partes de un problema, o los estudios de Valdivia que presentan un esquema práctico del que destacamos principios como la selección de estrategias o la formulación de definiciones.

Por tanto, atender a los planteamientos teóricos de otras disciplinas puede constituir, en determinados casos, una apuesta aconsejable para avanzar en el estudio de los fenómenos históricos, construyendo en el alumno y en el investigador unos esquemas de adecuación de contenidos que posteriormente pueden materializarse mediante la aplicación de técnicas de catalogación. Pero antes de llegar a eso, antes de que observemos en el lejano horizonte atisbos de trabajos conjuntos sustentados por herramientas propias de los sistemas de comunicación social, donde la historia vuelva a aspirar a ser "total" en tanto "integradora" de sucesivos esfuerzos que, por haberse realizado de forma normativizada, son compatibles con sus antecesores, enriqueciendo la visión más amplia de la problemática histórica específica con fuentes que despierten nuevas sensibilidades (y así, nuevas vías de estudio), miremos la realidad presente, donde se hace cada vez más necesaria la premisa sobre la que versa un estudio de la Facultad de Informática de la Universidad de Matanzas "Camilo Cienfuegos", donde un grupo de investigadores afirma lo siguiente:

Una prioridad que tiene la enseñanza de la Matemática, es la de contribuir a la formación y desarrollo del pensamiento lógico en nuestros estudiantes; de ahí que se trabaje en tres direcciones fundamentales, que son: desarrollo del pensamiento lógico, resolución de problemas y vinculación con la vida; de forma tal que permita a los alumnos, no sólo poder enfrentarse a la solución de problemas matemáticos, sino también, la de pensar de forma correcta ante la solución de cualquier tipo de problema que en la vida cotidiana enfrentan. ${ }^{5}$

Cambien algunos conceptos, apliquen sus propias categorías, traigan la cita a su propio contexto... y conviertan cada enunciado "en un metadato", en algo presente en todo momento en la actividad docente y en la investigación histórica.

\section{Bibliografía}

6.1 Libros:

MORENO CUADRO, F. (1991): Grabados andaluces de San Juan de la Cruz. Bibliografia sanjuanista de los siglos XVII-XVIII. Córdoba

NADAL, J. (2008): La Biblia Natalis. La Biblia de Jerónimo Nadal SJ. Universidad de Deusto. 
POLYA, G. (1989 $\left.{ }^{15}\right)$ : Cómo plantear y resolver problemas. México.

SANZ, C. (1962): Estampas de la Vida de la Santa Madre Teresa de Jesús, grabadas por los famosos artistas Cornelio Galle y Adrián Collaert. Madrid.

6.2 Publicaciones web:

AA.VV.: III Plan estratégico de REBIUN 2020. Disponible en http://www.mcu. es/bibliotecas/docs/MC/ConsejoCb/CTC/Bib_Univ/Planestrategico2020.pdf . [14-06-2013].

CABRERA SARMIENTO, L. La Heurística en la enseñanza de la Matemática. Disponible en http://www.bibliociencias.cu/gsdl/collect/libros/index/assoc/ HASH0174/138d28e8.dir/doc.pdf . [14-06-2013].

TORRES, Carlos (2008): La heurística (resolución de problemas) en la enseñanza de la matemática. Disponible en http://edumate.wordpress.com/2006/10/28/la-heuristica-resolucion-de-problemas-en-la-ensenanza-de-la-matematica/ [20-092013].

\section{Notas}

1 El presente trabajo ha sido posible gracias a la financiación de la Fundación Séneca, Agencia de Ciencia y Tecnología de la Región de Murcia, a través de una ayuda del Programa Séneca en los contratos entre los centros de investigación y el personal investigador en formación. Así mismo, forma parte de los proyectos de investigación HAR2010-21325-C-05-01: «Realidades familiares en conflicto: de la sociedad de los linajes a la sociedad de los individuos. Siglos XVII-XIX», del que es IP Francisco Chacón Jiménez, gracias a la financiación del MICINN, y del proyecto 15300/PHCS/10: «Nobilitas. Estudios y base documental de la nobleza del Reino de Murcia, siglos XV-XIX. Segunda fase: análisis comparativos», del que es IP Juan Hernández Franco, gracias a la financiación de la Fundación Séneca, Agencia de Ciencia y Tecnología de la Región de Murcia.

2 Las obras que hemos citado sobre Santa Teresa de Jesús y San Juan de la Cruz estaban localizadas en los fondos de la Biblioteca del Centro Internacional Teresiano Sanjuanista (Universidad de la Mística) de Ávila.

3 (Moreno, 1991: 40)

4 Por ello, explicábamos casi al inicio del presente trabajo que "conocer" los recursos de otras disciplinas no equivale a "dominarlos". El trabajo de un historiador se pone en valor cuando sabe valorar de igual forma el carácter profesional de quienes pueden participar en sus proyectos aportando herramientas de análisis, de catalogación, de presentación, de difusión de información, y hasta de programación del trabajo personal. Pero todo ello, claro está, ha de estar realizado y revisado por un especialista en la materia, al que el historiador ha de comunicar los presupuestos teóricos sobre los que se mueve. Curiosamente, se pondrá en evidencia un hecho: si el informático, pasado un tiempo, es capaz de definir el problema que se está analizando y comunicar su visión personal sobre los resultados que se están obteniendo, y tales resultados concuerdan con los que enuncia el investigador de Historia en su proyecto marco, el historiador ha logrado expresar sus metas y la importancia de su método a una comunidad científica amplia, que trasciende el círculo de colegas "de cotidiano (y a veces sospechoso) espaldarazo".

5 (Cabrera: 6) 


\section{El autor}

Francisco Javier Marin. Licenciado en Historia, tras obtener el título de Máster en el programa de doctorado en Historia Social Comparada por la Universidad de Murcia, inicia su período como investigador a través de la concesión de una beca FPI de la Fundación Séneca, que le habilita para desempeñar puestos docentes durante los cursos 2011-2013 en el Departamento de Historia Moderna, Contemporánea y de América de dicho centro, al que se encuentra adscrito, impartiendo clase tanto en las materias de Licenciatura como en los nuevos planes de Grado, así como intervenciones puntuales en calidad de profesor invitado para el mismo Máster. Ha realizado estancias internacionales, en Roma (Pontificia Universitá Gregoriana) y Amberes (Universiteit Antwerpen), y nacionales en Ávila (Centro Internacional Teresiano Sanjuanista. Universidad de la Mística). 